\title{
Toxicological and Biological Effects of Juvenile Hormone Mimic (JHM) Pyriproxyfen Against the Two Spotted Spider Mite, Tetranychus urticae Koch (Acari: Tetranychidae)
}

\author{
Hanan F. Abdel- Hafez; A.M. Khalil and H.M. El-Nenaey \\ Plant protection Research Institute, A.R.C, Dokki, Giza, Egypt.
}

\begin{abstract}
The present investigation was carried out to study the effect of Juvenile Hormone Mimic (JHM), Pyriproxyfen 10\% EC on toxicological and biological aspects of the two spotted spider mite, Tetranychus urticae Koch under laboratory conditions. The effects of Pyriproxyfen on mortality, life cycle, duration period, adult longevity, ovipositional period and female fecundity were evaluated. Results indicated that the candidate compound exhibited direct contact toxicity against all the different developmental stages of T. urticae, but protonymphs were more susceptible than adult females. The LC $\mathrm{L}_{50} \mathrm{~s}$ were 4.21 and $4.36 \mathrm{ppm}$ after $72 \mathrm{hr}$. post exposure for protonymphs and females, respectively. Also it had contact ovicidal activity influenced by egg age. 48-72 hr. eggs were significantly more sensitive than eggs of the other ages. According to $\mathrm{LC}_{50}$ values $\mathrm{LC}_{50}$ 's were $117.07,7.95$ and $2.91 \mathrm{ppm}$ for the three tested ages $(0-24 \mathrm{hr}, 24-48 \mathrm{hr}$ and $48-72 \mathrm{hr}$ old), respectively. Also, all the tested concentrations prolongated the incubation, larval, protonymphal and deutonymphal periods, but the maximum conc. level $(10 \mathrm{ppm})$ produced the highest increase. Also, the longevity of males and females were increased, the highest increase was observed with $10 \mathrm{ppm}$, it produced 23.42 days/ $\phi$ and 18.5 days/ $\hat{O}$ compared with 15.59 days/ $\not$ and 15.92 days/ $\widehat{\sigma}$ in the control. On the otherhand, oviposition periods were also influenced as concentration dependant response. The mean number of laid eggs/ $q$ were highly decreased as conc. increased, the highest

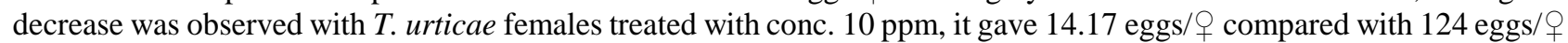
in untreated females. Results suggest that JHM, pyriproxyfen could be a good alternative and interesting component in Integrated Pest Management (IPM) for controlling TSSM, T. urticae and minimizing the usage of conventional pesticides.
\end{abstract}

Key Words: Tetranychus urticae, Pyriproxyfen, biological aspects.

\section{INTRODUCTION}

The red spider or the two-spotted spider mite (TSSM), Tetranychus urticae Koch (Acari: Tetranychidae) is a worldwide major pest species of agricultural crops (Ho, 2000 and Takafuji et al., 2000). It attacks many vegetable, ornamental, fruit and field crops.

Due to the harmful effect of the residual toxicity of the chemical neurotoxic insecticides on human and the environment, control agents with comparative safety are sought by searched entomologists. The systemic synthetic mimics of insect hormones, which are best known as insect growth regulators (IGRs) have been reported to be potent control agents against a number of pest insects of agricultural and fruit orchards (Fox, 1990). Pyriproxyfen 10\% EC was designed to model on the natural juvenile hormone. Therefore, it has similar effects on the insect's development and so called biorational pesticide. The mode of action of pyriproxfen on pest is quite different from those of neurotoxic insecticides such as organophosphates, carbamates and pyrethroids. This compound is almost non-toxic to non-target organisms and natural enemies such as parasites, predators and mites. (Neumann \& Guyer, 1987).

Therefore, the present investigation was carried out to study the effect of the JHM, pyriproxyfen on toxicological and biological aspects against $T$. urticae under laboratory conditions.

\section{MATERIALS AND METHODS}

\section{Tested mites:}

The colony of the two spotted spider mite, Tetranychus urticae was reared under laboratory conditions $25 \pm 2{ }^{\circ} \mathrm{C}$ and $70 \pm 5 \%$ R.H. at Plant Protection Research Institute.

\section{Test compound:}

Pyriproxyfen (Admiral 10\% EC), is a Juvenile Hormone Mimic (JHM). Chemical name is, 4phenoxyphenyl (RS)-2-(2-pyridyloxy) propyl ether, produced by Sumitomo Chemical Co.

\section{Toxicological studies:}

To examine the toxicological effect of the candidate compound against different developmental stages, i.e., adult females, protonymphs and eggs of T. urticae, three aqueous concentrations 10,5 and 2.5 ppm were used by diluting the formulated compound with distilled water. Six cotton leaf discs were considered as three replicates for each concentration. Sixty newly emerged adult females or protonymphs were used for each replicate. Also 60 separated eggs at three different ages (0-24 hrs, 24-48 hrs. and 48-72 hrs old) were treated with the three conc. of the candidate compound. Leaf-discs were placed upside 
down on moisted cotton wool in Petri dishes. Leafdisc surface carrying the different stages were directly sprayed using hand atomizer. Other three replicates were sprayed with water as control. All treatments were kept under laboratory conditions at $25 \pm 2^{\circ} \mathrm{C}$ and $70 \pm 5 \%$ R.H. Mortality percentage were recorded after 24, 48 and $72 \mathrm{hr}$. The average percent mortality were calculated and corrected using Abbott's formula (1925). To evaluate the ovicidal action of Pyriproxyfen against $T$. urticae egg at three different ages, treated and untreated eggs were held under laboratory conditions until hatching. Egg mortality and egg hatching were also recorded and corrected using Abbott's formula (1925). The $\mathrm{LC}_{50}, \mathrm{LC}_{90}$ and slope values were statistically calculated according to Finney (1971) using SPSS 10 software program.

\section{Biological studies:}

The treated adult females of $T$. urticae were examined daily to determine different biological aspects such as: duration period, ovipositional period, adult longevity, fecundity and fertility. Also, the life cycle and life span were determined.

\section{RESULTS AND DISCUSSION}

\section{Toxicological effect of JHM, Pyriproxyfen $10 \%$ EC against different developmental stages of $T$. urticae:}

Toxicity of the candidate compound against different stages, i.e., protonymphs, adult females and eggs of T. urticae are shown in (Tables 1, 2 and 3). Data in Table (1) indicated that mortalities of protonymphs increased as concentration and time after exposure increased. The mortality $\%$ of protonymph increased from $50 \%$ after 24 hrs. to $90.56 \%$ after 72 hrs., and from $24.44 \%$ after 24 hrs. to $50 \%$ after $72 \mathrm{hrs}$, and from $10.56 \%$ after $24 \mathrm{hrs}$, to $31.11 \%$ after $72 \mathrm{hrs}$ for the tested three conc., 10, 5 and $2.5 \mathrm{ppm}$, respectively. The highest mortality \% was observed when $T$. urticae protonymphs treated with $10 \mathrm{ppm}$. Also, mortalities of T. urticae females increased as concentration and time after treatment increase. (Table, 2). Mortality increased from $46.1 \%$ after $24 \mathrm{hr}$ to $90 \%$ after $72 \mathrm{hr}$., from $17.22 \%$ after $24 \mathrm{hr}$. to $41.67 \%$ after $72 \mathrm{hr}$. and from $11.67 \%$ after $24 \mathrm{hr}$. to $32.78 \%$ after $72 \mathrm{hr}$. The candidate compound exhibited direct contact mortality on protonymphs and adult females of TSSM, T. urticae, but protonymphs were more susceptible than adult females according to $\mathrm{LC}_{50}$ values (Tables 1 and 2). The $\mathrm{LC}_{50}$ 's were 4.21 and $4.36 \mathrm{ppm}$ after $72 \mathrm{hr}$ post treatment for protonymphs and females, respectively. Mean egg laid per female treated with the three tested conc. are shown in Table (2).Obtained results showed that a significant reduction in the mean number of eggs/ $q$ in all three tested conc. The highest reduction was observed when adult females treated with the lowest conc., $2.5 \mathrm{ppm}$, it produced 6.66, 7.87 and $9.49 \mathrm{egg} / 9$ after 24,48 and $72 \mathrm{hr}$., respectively compared with $42.33,56.67$ and 94.67 for untreated females.

Ovicidal effects of pyriproxyfen 10\% EC against three different egg ages of $T$. urticae are presented in Table (3).Results indicated that pyriproxyfen had an ovicidal activity influenced by egg age $48-72 \mathrm{hr}$. old eggs were significantly more sensitive than eggs of the other age classes. The $\mathrm{LC}_{50}$ 's were 117.07, 7.95 and $2.9 / \mathrm{ppm}$, respectively for the three egg ages i.e., (0-24 hr old), (24-48hr. old) and (48-72 hr. old). Also egg hatchability \% was reduced as concentration dependent response. The maximum conc. level $(10 \mathrm{ppm})$ produced the highest decrease in egg hatching against 48-72 hr. hold eggs. It caused $26.67 \%$ compared with $93.33 \%$ in untreated eggs (Table 3).

These results agree with previous studies of Saenz-de-cabezon, et al., (2002) who studied the effect of IGR, Trifluemuron on the developing stages of $T$. urticae. They found no differences in toxicity for larvae, protonymphs and deutonymphs, but immature stages were 3.8 times more susceptible than adults at $\mathrm{LC}_{50}$. Also the compound exhibited a direct contact ovicidal activity influenced by egg age. 48-72 hold eggs were significantly more sensitive than the other age classes. No hatch inhibition was observed in eggs laid by treated females using sublethal dose at two physiological times $(<12$ and 48-72hr old). In addition Schroeder et al., (1976) found that the foliage spray of diflubenzuron reduced the egg hatch of Diaprepes abbreviatus for 10 days after spraying.

\section{Biological aspects of Pyriproxyfen against different developmental stages of $T$. urticae: \\ Effects of the candidate compound on the duration periods of the developmental stages of T. urticae are presented in Table (4).}

Incubation period: All the tested conc. delayed the incubation period of T. urticae eggs/female compared to the control as concentration dependent response. The highest delayed effect was observed with the maximum conc. level (10 ppm); it produced 7.79 days compared with 4.13 days in control.

Larval period: As shown in Table (4) all the tested conc. of pyriproxyfen increased the larval period of the mite. The conc. 10ppm gave the highest increase of larval period; it increased from 1.81 days $/ P$ in control to 3.15 days $/ Q$ and from 1.64 days $/ \widehat{O}$ in control to 2.83 days/ $\widehat{O}$. 
Table (1): Toxicity response of $T$. urticae protonymphs treated with Pyriproxyfen

\begin{tabular}{ccccccc}
\hline Conc. (ppm) & \% Mortality after time post treatment (hours) & \multicolumn{3}{c}{ LC after 72 hr. } \\
\cline { 2 - 7 } & $24 \mathrm{hr}$. & $48 \mathrm{hr}$. & $72 \mathrm{hr}$. & LC $_{50} \mathrm{ppm}$ & LC $_{90} \mathrm{ppm}$ & Slope \\
\hline 10 & $50 \%$ & $76.67 \%$ & $90.56 \%$ & & & \\
\hline 5 & $24.44 \%$ & $37.22 \%$ & $50 \%$ & 4.21 & 11.59 & 2.91 \\
\hline 2.5 & $10.56 \%$ & $20.56 \%$ & $31.11 \%$ & & & \\
\hline Control & 0.0 & 0.0 & $1.67 \%$ & & & \\
\hline
\end{tabular}

Table (2): Toxicity response and mean \pm S.E eggs/ $Q$ of $T$. urticae female treated with pyriproxyfen

\begin{tabular}{|c|c|c|c|c|c|c|c|c|c|}
\hline \multirow{2}{*}{$\begin{array}{c}\text { Conc. } \\
\text { ppm }\end{array}$} & \multicolumn{3}{|c|}{$\%$ Mortality after } & \multirow{2}{*}{$\mathrm{LC}_{50}$} & \multirow{2}{*}{$\mathrm{LC}_{90}$} & \multirow{2}{*}{ Slope } & \multicolumn{3}{|c|}{ Mean \pm S.E eggs $/ \propto$ after } \\
\hline & $24 \mathrm{hr}$. & $48 \mathrm{hr}$. & $72 \mathrm{hr}$. & & & & $24 \mathrm{hr}$. & $48 \mathrm{hr}$. & $72 \mathrm{hr}$. \\
\hline 10 & $46.1 \%$ & $76.67 \%$ & $90.0 \%$ & & & & $7.31 \pm .059$ & $16.03=$ & $32.23 \pm 3.169$ \\
\hline 5 & $17.22 \%$ & $31.11 \%$ & $41.67 \%$ & 4.36 & 13.04 & 2.69 & $7.05 \pm 0.328$ & $8.92 \pm 0.155$ & $10.4 \pm 0.153$ \\
\hline 2.5 & $11.61 \%$ & $22.22 \%$ & $32.78 \%$ & & & & $6.66 \pm 0.367$ & $7.87 \pm 0.377$ & $19.49 \pm 0.382$ \\
\hline Control & 0.0 & 0.0 & 0.0 & & & & $47.33 \pm 1.44$ & $56.67 \pm 4.906$ & $94.67 \pm 3.953$ \\
\hline
\end{tabular}

Table (3): Ovicidal activity of pyriproxyfen against different egg ages of T. urticae

\begin{tabular}{|c|c|c|c|c|c|c|c|c|c|}
\hline \multirow[b]{2}{*}{$\begin{array}{l}\text { Conc. } \\
\text { ppm }\end{array}$} & \multicolumn{3}{|c|}{$0-24 \mathrm{hr}$. old eggs } & \multicolumn{3}{|c|}{$24-48$ hr. old eggs } & \multicolumn{3}{|c|}{$48-72 \mathrm{hr}$. old eggs } \\
\hline & $\begin{array}{c}\text { \% egg } \\
\text { Mortality }\end{array}$ & $\begin{array}{c}\% \text { egg } \\
\text { Hatchability }\end{array}$ & $\begin{array}{l}\mathrm{LC}_{50} \\
\mathrm{ppm}\end{array}$ & $\begin{array}{c}\text { \% egg } \\
\text { Mortality }\end{array}$ & $\begin{array}{c}\% \text { egg } \\
\text { Hatchability }\end{array}$ & $\begin{array}{l}\mathrm{LC}_{50} \\
\mathrm{ppm}\end{array}$ & $\begin{array}{c}\% \text { egg } \\
\text { Mortality }\end{array}$ & $\begin{array}{c}\% \text { egg } \\
\text { Hatchability }\end{array}$ & $\begin{array}{l}\mathrm{LC}_{50} \\
\mathrm{ppm}\end{array}$ \\
\hline 10 & $36.76 \%$ & $63.33 \%$ & & $56.67 \%$ & $43.33 \%$ & & $73.33 \%$ & $26.67 \%$ & \\
\hline 5 & $35.00 \%$ & $65.00 \%$ & 117.07 & $36.67 \%$ & $63.33 \%$ & 7.95 & $56.67 \%$ & $43.33 \%$ & \\
\hline 2.5 & $30.00 \%$ & $70.00 \%$ & & $33.33 \%$ & $66.67 \%$ & & $48.33 \%$ & $51.67 \%$ & 2.91 \\
\hline Control & $3.33 \%$ & $96.67 \%$ & & $5.0 \%$ & $95.00 \%$ & & $6.67 \%$ & $93.33 \%$ & \\
\hline
\end{tabular}

Table (4): Efficiency of Pyriproxyfen 10\% EC on duration periods of life cycle of T. urticae

\begin{tabular}{|c|c|c|c|c|c|}
\hline \multirow{2}{*}{ Sex } & \multirow[t]{2}{*}{ Stages } & \multicolumn{3}{|c|}{ Duration (days) \pm S.E } & \multirow{2}{*}{ Control } \\
\hline & & 10 & 5 & 2.5 & \\
\hline \multirow{5}{*}{$\begin{array}{c}\stackrel{q}{+} \\
\text { Female }\end{array}$} & Incubation period & $7.79 \pm 0.312$ & $7.12 \pm 0.005$ & $4.61 \pm 0.112$ & $4.13 \pm 0.0519$ \\
\hline & Larva & $3.15 \pm 0.011$ & $2.69 \pm 0.080$ & $2.13 \pm 0.0272$ & $1.81 \pm 0.0299$ \\
\hline & Protonymph & $2.5 \pm 0.1452$ & $2.3 \pm 0.0942$ & $2.3 \pm 0.047$ & $1.28 \pm 0.132$ \\
\hline & Deutonymph & $3.02 \pm 0.034$ & $2.23 \pm 0.087$ & $1.94 \pm 0.0838$ & $1.77 \pm 0.0124$ \\
\hline & Life cycle / 9 & $15.79 \pm 0.185$ & $15.01 \pm 0.573$ & $10.98 \pm 0.514$ & $8.98 \pm 0.226$ \\
\hline \multirow{5}{*}{$\begin{array}{c}\hat{\sigma} \\
\text { Male }\end{array}$} & Incubation period & $6.13 \pm 0.0098$ & $5.18 \pm 0.109$ & $4.31 \pm 0.049$ & $3.17 \pm 0.04$ \\
\hline & Larva & $2.83 \pm 0.060$ & $2.23 \pm 0.0606$ & $1.87 \pm 0.0236$ & $1.64 \pm 0.0072$ \\
\hline & Protonymph & $2.65 \pm 0.287$ & $2.23 \pm 0.072$ & $1.77 \pm 0.038$ & $1.31 \pm 0.076$ \\
\hline & Deutonymph & $2.8 \pm 0.078$ & $2.28 \pm 0.061$ & $1.81 \pm 0.09$ & $1.58 \pm 0.05$ \\
\hline & Life cycle/ $\hat{\jmath}$ & $14.41 \pm 0.434$ & $11.91 \pm 0.3026$ & $9.76 \pm 0.2006$ & $7.7 \pm 0.1732$ \\
\hline
\end{tabular}

Table (5): Effect of Pyriproxyfen 10\% EC on ovipositional periods and fecundity of T.urticae female

\begin{tabular}{cccccc}
\hline \multirow{2}{*}{$\begin{array}{c}\text { Conc. } \\
\text { ppm }\end{array}$} & \multicolumn{2}{c}{ Ovipositional period mean \pm S.E (days) } & \multicolumn{2}{c}{ Fecundity mean \pm S.E } \\
\cline { 2 - 5 } & Pre-oviposition & Oviposition & Post-ovipostion & Eggs/o & \% Hatchability \\
\hline 10 & $3.02 \pm 0.034$ & $17.3 \pm 0.464$ & $3.1 \pm 0.188$ & $14.17 \pm 0.495$ & $35.71 \%$ \\
\hline 5 & $2.37 \pm 0.118$ & $14.57 \pm 0.259$ & $2.14 \pm 0.0047$ & $41.13 \pm 0.459$ & $48.63 \%$ \\
\hline 2.5 & $2.06 \pm 0.126$ & $14.00 \pm 0.205$ & $2.2 \pm 0.0816$ & $70.47 \pm 0.724$ & $63.86 \%$ \\
\hline Control & $1.37 \pm 0.078$ & $12.73 \pm 0.276$ & $1.49 \pm 0.173$ & $124 \pm 7.9$ & $95.16 \%$ \\
\hline
\end{tabular}


Table (6): Effect of Pyriproxyfen 10\% EC on adult longevity and life span of T. urticae males and females.

\begin{tabular}{|c|c|c|c|c|}
\hline \multirow{2}{*}{$\begin{array}{l}\text { Conc. } \\
\text { (ppm) }\end{array}$} & \multicolumn{2}{|c|}{ Longevity \pm S.E (days) } & \multicolumn{2}{|c|}{ Life span \pm S.E (days) } \\
\hline & q & $0^{\lambda}$ & q & $\hat{0}$ \\
\hline 10 & $23.42 \pm 0.686$ & $18.5 \pm 0.232$ & $39.21 \pm 0.871$ & $32.91 \pm 0.716$ \\
\hline 5 & $19.08 \pm 0.3811$ & $18.42 \pm 0.252$ & $34.09 \pm 0.954$ & $30.33 \pm 0.554$ \\
\hline 2.5 & $18.26 \pm 0.412$ & $17.35 \pm 0.088$ & $29.24 \pm 0.926$ & $27.11 \pm 0.288$ \\
\hline Control & $15.59 \pm 0.527$ & $15.92 \pm 0.0195$ & $24.57 \pm 0.753$ & $23.62 \pm 0.368$ \\
\hline
\end{tabular}

Protonymphal period: The three treated conc. caused prolongation of the protonymphal period of T. urticae. The maximum protonymphal period was 2.65 days $/ \widehat{O}$ and 2.5 days/ +9 at conc. 10ppm compared with 1.31 days/ $\widehat{O}$ and 1.28 days/ $q$ in the control, respectively.

Deutonymphal period: The tested conc. of pyriproxyfen increased the deutonymphal period (Table 4). The maximum conc. level (10 ppm) produced the highest increase in deutonymphal period as; it gave 3.02 days/ $q$ compared with 1.77 days/ $Q$ in untreated one.

Life cycle: The mean life cycle duration of T. urticae $\delta$ and $q$ are shown in Table (4). The maximum increase in life cycle was observed at conc. $10 \mathrm{ppm}$, it produced 15.79 days/ $O$ and 14.41 days $/ \hat{O}$ compared with 8.98 days/ + and 7.7 days/ $\delta$ in the control, respectively.

Ovipositional periods and fecundity: Ovipositional periods and fecundity of $T$. urticae females treated with three different conc. of pyriproxyfen are shown in Table (5).

Pre-oviposition period: Data indicated that the time required for maturation of females mite ovaries treated with tested compound increased as conc. increase. The maximum time required for maturation of females T. urticae ovaries treated with conc. 10 ppm was 3.02 days compared with 1.37 days in untreated females.

Oviposition period: Also, the mean oviposition period increased when adult females of $T$. urticae were treated with all the tested conc. of pyriproxfen as shown in Table (5). The highest increase observed at conc. $10 \mathrm{ppm}$, it produced 17.3 days compared with 12.73days in untreated females.

Post-oviposition period: The post oviposition period of $T$. urticae females treated with the three conc. was increased as conc. increase. The maximum conc. level, $10 \mathrm{ppm}$ produced the highest increase; it gave 3.1 days compared to 1.49 days in untreated females.
Female fecundity: The number of laid eggs/ $q$ was highly decreased as conc. increased (Table 5). The highest decrease in mean laid eggs/ 9 was observed when female treated with conc. $10 \mathrm{ppm}$; it gave 14.17 eggs/ q compared with 124 eggs/untreated o females. Also, the tested conc. caused significant reduction in the viability of eggs deposited by treated females; the highest reduction in hatchability was $35.71 \%$ at conc. 10 ppm in comparison with $95.16 \%$ in the control.

Adult longevity: The tested compound increased adult females and males longevity (Table, 6). The highest increase in longevity was observed at conc. $10 \mathrm{ppm}$; it gave 23.42 days/o and 18.5 days/ $ठ$ compared with 15.59 days/ $q$ and 15.92 days / $\delta$ in untreated ones.

Life span: Also Life span increased as conc. increased (Table, 6). The maximum conc. $10 \mathrm{ppm}$ gave 39.21 days/ and 32.91days/ o compared with 24.57 days $/ \uparrow$ and 23.62 days $\delta$ in the control.

The present study clearly revealed that the JHM, Pyriproxyfen has contact toxicity against different developmental stages of $T$. urticae which stop feeding within hours of treatment and die 2-3 days post exposure. No larval, nymphal molting was observed. In addition it had latent effects on female oviposition and fecundity i.e., decreased the number of eggs laid per females, and increased adult males and females longevity. Our results agree with previous studies of El-Banhawy \& Amer (1992), Rani \& Mohan (1998) and Akashe (2004), who indicated that treatment with IGR, flufenoxuron increased the duration periods of developmental stages and affected reproduction of $T$. urticae females. Also treated females produced nonviable eggs and viability increased as the conc. was reduced to $1 \mathrm{ppm}$. Also Saenz Cabenzon et al., (2006) observed that the net reproductive rate and the intrinsic rate increased and the finite rate of T. urticae female treated with Triflumeron were lower than in those untreated resulting in a reduction of population growth. In addition, Naher et al., (2006) found that treating T. urticae with two IGRs, Diflubenzuron and Triflumeron significantly extended the duration 
periods of different developmental stages except deutonymph to adult. Ramos \& Castanera (2003) tested the effect of Halofenozide, Pyriproxyfen and Hexaflumuron against the storage mite, Tyrophagus putrescentiae. The organophosphate, Chlorpyrifos was used as a stander. They observed that all IGRs significantly increased the developmental time of immature stages at doses higher than $1.000 \mathrm{ppm}$. Pyriproxyfen and Halofenozide yielded morality rates of immature stages similar to that obtained with Chlorpyrifos, with values near $100 \%$ at $10.000 \mathrm{ppm}$ and at $1.000 \mathrm{ppm}$. Also, pyriproxyfen reduced fecundity at $1.000 \mathrm{ppm}$ whereas it required 10.000 ppm of Chlopyrifos.

These results suggest that Pyriproxyfen could be a good alternative and interesting incorporation in IPM programs for controlling $T$. urticae and to help minimizing the usage of conventional pesticides.

\section{REFERENCES}

Abbott, W.S. 1925. A method of computing the effectiveness of an insecticide. J. Econ. Entomol., 18: 265-267.

Akashe, V.B. 2004. Management of spotted spider mite Tetranychus urticae Koch of Rose during summer season. J. Maharashtra. Agri- Univ., 29 (1): 96-97.

El-Banhawy, E.M. and Amer, S.A. 1992. Retarded biology of the TSSM, T. urticae Koch after exposure to the anti-moulting compound, flufenoxuron under laboratory conditions. Appl. Entomol. Zool., 65 (7): 126-128.

Finney, D. J. 1971. Probit Analysis. $3^{\text {rd }}$ Ed. Cambridge Univ. Press. London. 333pp.
Fox, P. 1990. Insect Growth Regulators. PJB. Publ. Ltd. Richmond, UR. 102pp.

Ho, C.C. 2000. Spider mite problems and control in Taiwan. Exp. Appl. Acarol., 24: 453-462.

Naher, N.; Islam, T.; Haque, M.M. and Parween, S. 2006. Effects of native plants and IGRs on the development of $T$. urticae Koch (Acari: Tetranychidae). J. Zool. Rajshahi Univ., 25: 1922.

Neumann, R. and Guyer, W. 1987. Biochemical and toxicological difference in mode of action of the benzoylureas. Pestic. Sci., 20:147-156.

Ramos, I.S. and Castanera, P. 2003. Laboratory Evaluation of Selective Pesticides against the storage mite, Tyrophagus putrescentiae (Acari: Acaridae) J. Medi. Entomol., 40 (4): 475-481.

Rani, B. J. and Mohan, N. J. 1998. Cascade, a potential acaricide for management of two-spotted spider mite on Rose. Insect. Environ., 4 (1): 12-16.

Saenz de Cabenzon, F. J.; Moreno, I.P. and Marco, V. 2002. Effects of Triflumuron on the TSSM, T. urticae (Acari: Tetranychidae) Exp. Appl. Acarol., 26 (1-2): 71-78.

Saenz de Cabenzon, F. J; Moreno, I. P.; Marco, V. and Moreno, M.V. 2006. Influence of sublethal exposure to triflumuron on the biological performance of $T$. urticae Koch. http://www.fotosaf .com/siarIST/siar 04208.html.

Schroeder, W. J.; Beavers, B. J.; Sutton, R.A. and Selhime, A.G. 1976. Ovicidal effect of Thompson-hayard TH-6040 in Draprepes abbreriatus on citrus in Florida. J. Econ. Entomol., 69 (6): 780-782.

Takafuji, A.; Ozawa, A.; Nemoto, H. and Gotoh, T. 2000. Spider mites of Japan: their biology and control. Exp. Appl. Acarol., 24: 319-335. 